\title{
On the Fedorov Prize Competition Held by the Russian Academy of Sciences
}

PACS numbers: 01.60.+q

DOI: $10.1134 / \mathrm{S} 1063774509030298$

The Division of Physical Sciences of the Russian Academy of Sciences announces that the Fedorov Prize Competition will be held in 2009.

The Fedorov Prize is awarded every three years for outstanding scientific works, discoveries, inventions, and series of scientific works in crystallography. Each work is usually presented in the name of one author. For collective studies, no more than three main authors should be proposed.

The right to propose candidates for the prize is granted to

(1) academicians and corresponding members of the Russian Academy of Sciences;

(2) scientific institutions and institutes of higher education;

(3) scientific councils of the Russian Academy of Sciences and other departments working on fundamental scientific problems;

(4) scientific communities and technical communities of engineers;

(5) scientific and technical councils of ministries and departments, as well as technical councils of industrial enterprises and designer's offices.

The necessary documents for proposing a candidate for the prize should be presented to the Shubnikov Institute of Crystallography of the Russian Academy of
Sciences (Leninskiu pr. 59, Moscow, 119333 Russia) addressed "To the Pedorov Prize Competition." The following documents are required:

(1) a presentation justifying the nomination, including the scientific characterization of the work and its importance for the development of science and the national economy;

(2) the scientific work (or series of works) presented (in three copies);

(3) data about the author (a list of main their scientific works, discoveries, and inventions; affiliation and post; home address; and work and home telephone numbers);

(4) a certificate confirming that the work presented has not already been awarded state or honorary prizes.

Works that have already been awarded state or honorary prizes are not accepted for the Fedorov Prize.

The documents must presented no later than September 22, 2009.

Division of Physical Sciences of the Russian Academy of Sciences

Translated by Yu. Sin'kov 